${ }^{I}$ Universidade Federal de Campina Grande, Brasil

aguiar.mauricio.m@gmail.com

\title{
MACHADO DE ASSIS EM PERSPECTIVA: OS OLHARES DIVERGENTES DE SÍLVIO ROMERO E JOSÉ VERÍSSIMO
}

José Veríssimo e Silvio Romero são os principais nomes da crítica literária de fim do século XIX e início do XX. Ambos dedicaram-se a escrever versões da história literária brasileira e foram pioneiros devido à maior sistematicidade de seus estudos. José Veríssimo (I857-I9I6) e Sílvio Romero (I85I-I9I4) possuem orientação intelectual inicial muito similar, alicerçada por específicos estudos antropológicos e sociológicos do século XIX permeados de premissas evolucionistas. E estrearam como críticos com o intuito de reformular os estudos da cultura, principalmente a literatura, a partir de alguns destes critérios científicos do período.

Não é raro encontrar diversos pontos de desavença, que se acentuam na maturidade, entre José Veríssimo, paraense de Óbidos, e Sílvio Romero, sergipano de Lagarto. Entre as divergências mais comuns podem ser destacadas a forma de classificação da história literária, quais nomes seriam dignos de representar a literatura brasileira e qual o primeiro escritor "nacional". Contudo, a questão fundamental em que divergem não diz respeito somente ao tratamento do objeto com que lidavam, vai um pouco além e se reflete na organização da obra e também da vida de cada um. Talvez seja possível identificar a principal oposição entre eles a partir da maneira com que ambos parecem responder a seguinte questão: qual a função efetiva do crítico literário? Suas respostas transpuseram a discussão teórica e adentraram em princípios de valor que guiavam a conduta e a pena de cada um, pois tal 
questão oferecia a oportunidade para ambos defenderem suas compreensões específicas sobre os papéis do intelectual e do artista na esfera pública.

Essa principal divergência torna-se ainda mais nítida quando o julgamento crítico desviava o olhar do passado e considerava autores que lhes eram contemporâneos, assim como acontece em relação a Machado de Assis. A análise dos estudos críticos de Silvio Romero e José Veríssimo sobre Machado de Assis, desta maneira, é um caminho interessante para se compreender os modelos de literato brasileiro defendidos por ambos, em um momento capital da construção de sentidos narrativos para a história brasileira a partir da literatura nacional. Pretendo apresentar e confrontar as imagens públicas de Machado de Assis elaboradas pelos dois intelectuais, e identificar, a partir de suas principais divergências, alguns pressupostos estéticos e éticos que orientaram a composição de seus retratos.

Enquanto Machado é retratado em uma chave negativa por Sílvio Romero, para José Veríssimo o primeiro presidente da Academia Brasileira de Letras ocuparia um lugar especial na história da literatura nacional; divergência de veredictos que, como já foram amplamente documentados, resultaria, também, das relações travadas entre os dois críticos com o próprio Machado de Assis. Parte dos autores atribui essa classificação tão diversa de Machado, realizada pelos mais renomados críticos de seu período, ${ }^{\mathrm{I}}$ ao lugar ao qual cada um ocupa nas "panelinhas", como se o circuito de amizades determinasse o elogio ou repúdio a alguma obra e autor. Seguindo essa perspectiva, João Cezar de Castro Rocha denominou o comportamento da intelectualidade brasileira de fim de século XIX a partir do conceito de "cordialidade", "[...] cujos argumentos e ideias alimentam-se mais do coração do que da razão" (Rocha, 2004: 253). Assim, as indisposições eram essencialmente pessoais, transformando as redes de amizades em uma espécie de organizador da vida intelectual, capaz de constituir as oposições à revelia de um tratamento mais rigoroso das ideias que se discutem, cujo maior resultado se reflete nas famosas "polêmicas". Com algumas diferenças, Roberto Ventura identificou, a partir das polêmicas, esse mesmo traço da intelectualidade brasileira, o caráter pessoalizado das discussões literárias, que, para ele, seria resultado da fusão entre uma modernização do conhecimento e as formas tradicionais de vida social. Uma fusão entre modos de vida tradicionais representados pela oralidade da poesia popular e pelas "leis" que se constituem sob uma lógica familiar - portanto, carente de princípios gerais que os governem - e, de outro lado, formas modernas de percepção do mundo, representadas pela absorção da retórica jurídica aliada a uma compreensão evolucionista do embate, proveniente dos postulados científicos em voga, onde necessariamente a melhor ideia advém da disputa (Ventura, I99I: Io). João Cezar de Castro Rocha e Roberto Ventura parecem apontar, por caminhos diferentes, para uma mesma direção: a vida intelectual brasileira era permeada de vicissitudes de cunho 
pessoal, em que a discussão de ideias é um canal para expressar as rixas e elogios exagerados desdobrados das relações pessoais. O ponto é extremamente interessante, visto que identifica no comportamento intelectual brasileiro de fim de século XIX uma lógica de organização peculiar, mas que pode incorrer no perigo de se esvaziar toda a discussão teórica devido à preponderância dada às relações pessoais. Ainda que se privilegie essa "estrutura" dos laços afetivos é importante investigar quais afinidades são eleitas por determinado intelectual e o predispõem à amizade literária. Quais valores constituem esses vínculos e como viabilizam a formação de certa visão de mundo (Weber, 1992). Com base nessa premissa, é fundamental qualificar as "relações pessoais" - pois este conceito não se esgota apenas ao se determinar as redes entre os intelectuais e, sim, através da identificação dos princípios que regem a cumplicidade entre eles -, e desvendar o sentido que tal espécie de associação porta.

Considerar a relação pessoal a partir do conceito de afinidade introduz uma série de outros matizes necessários à compreensão do mundo intelectual brasileiro desse período. Em primeiro lugar, é importante restringir o universo de significações e pôr a investigação sob uma vigilância hermenêutica, ou seja, tentar inscrever as ações e conhecimentos dos sujeitos envolvidos a partir de seu tempo e ambiente. Pois as afinidades de fim de século XIX no Brasil obedecem a um conjunto de valores precisos, não passíveis de serem transportados para outras culturas e nem outros tempos históricos sem serem devidamente justificados. Essa hermenêutica força, ainda, a limitar também o campo de observação, pois os valores e visões de mundo que podem explicar as atitudes presentes nas polêmicas e ensaios dos críticos mencionados são circunscritas a um determinado círculo social, um universo especificamente intelectual, com pretensões de se diferenciar do seu entorno e desenvolver uma linguagem capaz de filtrar tudo que lhe é externo a partir de um conjunto de prerrogativas de valor e conhecimento. O que significa dizer que tais "sentidos" são compartilhados, disputados e expressos dentro de um determinado ambiente e envolvendo mais diretamente apenas certas pessoas com características específicas. Mesmo que os temas desenvolvidos impliquem grandes interpretações nacionais, que é o caso de críticos como José Veríssimo e, principalmente, Sílvio Romero, estas interpretações foram geradas a partir de convenções de tal círculo de intelectuais, envolvendo específicos repertórios teóricos e formas de vida.

O que está em jogo na comparação entre Sílvio Romero e José Veríssimo à luz dessas categorias e conceitos é destacar com maior nitidez uma rivalidade que extrapola a simples luta de vaidades. A negociação estabelecida entre estes dois críticos envolve tanto princípios de valor, configurados no lugar que a crítica ocupa diante da sociedade, como, ainda, uma disputa pela forma de convivência intelectual, por padrões de conduta legítimos. 
Trata-se, portanto, de um processo de definição mesma do significado de ser intelectual e artista em meio à sociedade brasileira, fator que ganha relevo na comparação dos seus retratos de Machado de Assis. Não deve ainda passar despercebido o caráter emblemático dessa discussão em torno do escritor fluminense se deflagrar com o bombástico livro de Sílvio Romero publicado em I897, no mesmo ano em que Machado de Assis se tornaria o primeiro presidente da Academia Brasileira, em pleno processo de consagração em vida (Romero, I992). Não é uma mera coincidência de datas, pois se trata de uma disputa pela legitimidade da imagem do presidente como representante literário do país, e do tipo de representação simbólica que sua imagem porta.

Uma característica importante dos seus textos é que ambos os críticos literários escreveram ensaios. Através dessa forma de escrita é possível mesclar análises e observações de cunho mais pessoal, próximo a uma "conversação", para assim construir um relacionamento mais direto com o artista retratado. Uma espécie de pretensão em desvendar a "personalidade" do criticado, e aos poucos elaborar um "personagem" cuja vida e obra são dotadas de sentido próprio, que valida as observações do crítico. Por isso, ao passo que o ensaio de crítica literária deixa "transparente" um determinado autor e esmiúça peculiaridades e temperamento, ele expõe também o crítico. Ao traçar o perfil de outrem, o ensaísta define simultaneamente a si próprio, e revela a partir de suas categorias as bases de seu entendimento do mundo, deixando evidentes as características que aproximam ou distanciam crítico e criticado. E não é raro que seja este mesmo o propósito, medir-se com o outro e definir a si próprio ao mesmo tempo em que analisa este "personagem". Deste modo, o ensaio da crítica brasileira do XIX preservou a principal aspiração do ensaio: a interpretação da arte e do artista com a finalidade de educar o gosto, a imaginação e, ainda, o comportamento. Lukács, provavelmente inspirado nas discussões de Simmel sobre a sociabilidade (Simmel, 2006: 80), abordou o cerne desta questão em seu estudo sobre a natureza do ensaio ao apontar que o objetivo do ensaísta consiste na busca pela "ilusion of truth" que conduz o estudioso à apreensão da "vida" do autor analisado, uma espécie de verdade mítica mais dirigida pelos questionamentos da geração do próprio crítico, com a intenção de prover seus contemporâneos e a si mesmo de símbolos de vida (life-symbols), guias para a modelagem de suas próprias personalidades (Lukács, I980).

Dessa maneira tem-se, de um lado, a percepção de que o trabalho do crítico se baseia na produção de modelos de comportamento diante das próprias contingências históricas na qual está imerso - símbolos de vida -, e, de outro lado, que a construção desse modelo de conduta está fortemente correlacionada com a própria visão de mundo do crítico, justificando o tipo de relação que se estabelece com o criticado - as afinidades. A partir dessas considerações, os ensaios e polêmicas de José Veríssimo e Sílvio Romero, que 
mencionam o autor de Quincas Borba de forma direta, podem conter as descrições do caráter de Machado que legitimam suas próprias posturas como intelectuais, seja através da transformação do escritor fluminense em um símbolo de vida (José Veríssimo), ou pela construção do antimodelo (Sílvio Romero). Mas, para isso ganhar contornos mais claros é necessário dimensionar esses pontos a partir das produções dos dois críticos. As páginas que se seguirão representam uma tentativa de construir, a partir da referência às obras dos dois autores, o argumento de forma satisfatória, ainda que sem pretensões sistemáticas.

\section{UMA FACE DE MACHADO: SÍLVIO ROMERO}

José Veríssimo e Sílvio Romero são importantes nomes do processo de renovação da crítica literária brasileira, encarregados de trazer para as análises literárias uma maior sistematização teórica. Fazem parte da onda cientificista que passou a compor a base do conhecimento de diversos intelectuais no país no decênio de I868-I878, em que obras evolucionistas, positivistas, darwinistas, naturalistas e estudos de folclore ${ }^{2}$ tornaram-se leitura obrigatória para praticamente toda uma geração. Até mesmo algumas referências da nova crítica literária, como Taine, que adaptava esses recentes modelos teóricos para o estudo da literatura, já eram citados, principalmente por Sílvio Romero. ${ }^{3}$ Ambos os autores, portanto, surgem no bojo desse desejo por transformação, tanto no plano teórico como em termos políticos, “[...] datam desta época os primeiros sintomas efetivos de uma ampla modificação na maneira de ver e discorrer sobre o país [...]" (Barbosa, I974: 27). A estreia de Sílvio Romero ocorre em I869, aos dezoito anos, e nos primeiros anos que se seguem lança-se simultaneamente como poeta e crítico literário. Em um dos seus primeiros ensaios já critica Machado de Assis, ainda em maio de 1870 no jornal A Crença, quando assinava Silvio Ramos, falando do poeta fluminense a respeito do "seu lirismo subjetivista e o seu humorismo pretensioso" (Romero, I878: 242). Outro momento em que volta a se referir ao escritor fluminense é em prefácio do seu livro Cantos do fim do século, publicado em I878, 4 intitulado "A poesia de hoje", uma reedição de artigo escrito em I 873 publicado no jornal 0 Movimento, texto em que Romero critica abertamente o romantismo, incluindo nessa escola o próprio Machado de Assis. Ali defende uma poesia baseada em novo lirismo, desapegado da "decadente escola", e inspirado em ideias de cunho científico.

Machado de Assis, contradizendo um pouco seu pendor antipolemista, faz a recepção de "Cantos do fim do século" em "A nova geração",5 e desqualifica o novo poeta ao destacar o descompasso entre a ideia que brota da cabeça e sua forma de expressão. Os duros termos empregados indicam que não é propriamente do poema que Machado faz essas observações, pois po- 
deria ter sido um pouco mais complacente com um iniciante, aliás como o é com outros nomes da nova geração. A maneira direta de anunciar o "desastre literário" parece ser uma resposta ao prefácio, em que as ideias de Sílvio Romero ficam mais claramente definidas e o seu tom agressivo é mais evidente. Parece haver no ensaio de Machado uma lição aos jovens, principalmente a Sílvio, em duplo sentido: o primeiro, demonstrando que há sempre aspectos de continuidades entre movimentos históricos, o que torna as pretensões radicais de ruptura um exagero, e, em segundo lugar, que há uma descompostura e deselegância no tratamento dos jovens dirigido aos velhos intelectuais e artistas. Eis as palavras de Machado:

\begin{abstract}
A nova geração chasqueia às vezes do Romantismo. Não se pode exigir da extrema juventude a exata ponderação das cousas; não há impor a reflexão ao entusiasmo. De outra sorte, essa geração teria advertido que a extinção de um grande movimento literário não importa a condenação formal e absoluta de tudo o que êle afirmou; alguma cousa entra e fica no pecúlio do espírito humano. Mais do que ninguém, estava ela obrigada a não ver no Romantismo um simples interregno, um brilhante pesadelo, um efeito sem causa, mas alguma cousa mais que, se não deu tudo o que prometia, deixa quanto basta para legitimá-lo. [...] Mas não há só inadvertência naquele desdém dos moços; vejo aí também um pouco de ingratidão. A alguns dêles, se é a musa nova que os amamenta, foi aquela grande moribunda que os gerou; e até os há que ainda cheiram ao puro leite romântico (Machado de Assis, s/d: I24-I25).
\end{abstract}

Além de expor os fatos que de certa maneira explicam a réplica de Sílvio Romero inscrita em seu livro quase vinte anos depois do ensaio "A nova geração", de Machado, há, desde o início, uma divergência crucial movendo esta animosidade entre os dois. As ideias de Sílvio e, principalmente, a forma como ele as expõe parecem chocar-se com outra forma de compreender o mundo e posicionar-se. Haveria, portanto, alguma possível conexão entre o tipo de ideia desenvolvida por Sílvio Romero e sua atitude alheia às conveniências da sociabilidade literária ${ }^{6}$ Ou seja, método e modo de vida estariam intimamente ligados? Suponho que sim, mas é importante abordar essa última questão com um pouco mais de cuidado.

A crítica naturalista de Sílvio Romero foi resultado direto das transformações do pensamento no período, em que a "realidade" tornava-se objeto literário, um tipo de obsessão em escrever o que se "vê", sem os supostos vícios de imaginação do Romantismo, que, segundo ele, cultivava um estado de melancolia variando da extrema tristeza para a extrema alegria (Candido, I988: 39). E para apreender esta "realidade" seria necessário policiar o juízo individual e amparar a descrição do real no método científico. A forma encontrada por Romero, de inspiração tainiana, sujeitava o intelectual à observação do meio, da raça e da evolução histórica, como garantias de que por meio destes seria possível determinar o comportamento e forma de pensar de um povo.7 O "meio" corresponde aos determinismos geográficos e tem como principal fator o clima, que deixava sua marca no comportamento co- 
letivo e aos poucos condicionava a organização da vida de todos; a "evolução histórica" diz respeito aos fatos, tidos como acontecimentos que mudavam o rumo político e social deste mesmo povo; a "raça", que é vista por Romero como o principal elemento de explicação para o Brasil, teria como parâmetro teórico uma correlação entre fisiologia e caráter, em que as características físicas imprimem disposições de personalidade específicas. A literatura também seria condicionada por esses fatores, e expressaria o temperamento coletivo, revelando a índole do povo, como uma espécie de documento ou retrato que registraria um estágio da evolução nacional. Assim, o pensamento de Sílvio Romero possuía uma orientação nacionalista, ou seja, analisava a história do país através de um sentido narrativo, no qual se devia contar a formação deste povo e sua raça. Dessa forma a literatura, produto da psicologia nacional - dos condicionamentos históricos, biológicos e geográficos torna-se um importante representante da cultura, um objeto primordial para o entendimento e apreensão dessa índole popular. Tanto a literatura como os literatos são um "meio" para compreender a sociedade brasileira e a formação nacional, objetivo maior de toda obra de Sílvio Romero (Rocha, 2004: 259).

A tradução da teoria naturalista para o caso brasileiro ganha nos textos do crítico sergipano um sentido bastante específico. Apesar de toda pretensão de ruptura em relação ao Romantismo, o modo como trabalhou sua temática o conduzia para a mesma direção da "decadente escola", a afirmação da especificidade local diante da humanidade, ou seja, a nação como fundamento último dos processos sociais. Desse modo, pulsaria em sua obra a busca pela peculiaridade brasileira, aquilo que a punha em situação diferenciada frente a outras nações e que caminhava para a produção de uma arte "autêntica". Para Sílvio Romero, entretanto, a "autenticidade" nacional precisava ser perseguida mediante um caminho diverso: a questão racial. Um aspecto de suas ideias que, segundo Antonio Candido, antecipa o cerne da discussão de Gilberto Freyre nos anos I930 do século XX (Candido, I988: $60)$, pois trata a cultura brasileira mediante a observação da mestiçagem. Bem diferente da tentativa de identificar nos índios a origem étnica do brasileiro, tal qual realizado pelos românticos, Romero pensava a formação do temperamento do brasileiro a partir da concepção de mistura entre raças, em que o elemento indígena é tratado como insignificante diante do negro e, principalmente, do português. Mas, e nesse ponto entra em forte contato com a perspectiva de Gilberto Freyre, não se tratava de abordar somente o cruzamento biológico entre raças e, sim, uma espécie de "mestiçagem moral", em que formas de comportamento começavam a se desenhar com o contato entre as culturas, com destaque especial para a relação entre o negro e o português. ${ }^{8}$ O mulato seria o produto físico e moral da relação entre as raças, portanto um novo tipo em formação, desenvolvendo costumes e linguagens individualizadas de uma incipiente tradição verdadeiramente brasileira. 
Para Sílvio Romero, a mestiçagem é o fator determinante da índole do brasileiro e capaz de explicar, assim, o perfil de literatura que se desenvolvia. Com esta nova raça ainda em processo de formação, portanto pouco individualizada, o povo viveria segundo uma frágil tradição nacional, o que a deixaria suscetível à imitação de costumes estrangeiros, principalmente o gosto e refinamento francês. A imitação seria, assim, um resultado dessa insegurança de caráter, da imprecisão do comportamento, e boa parte da literatura brasileira padeceria dessa inconsistência do temperamento, "fonte de perturbações e desequilíbrios" (Romero, I978: 62). De um lado teríamos uma sociedade de aparências, "para inglês ver", ${ }^{9}$ e, de outro, uma sociedade que já dava mostras de sua índole em processo de autonomia. Sílvio Romero enxergava essa mesma dicotomia instalada no plano literário, pois também haveria intelectuais que reproduziam as modas europeias. Apenas alguns ensaiavam uma forma literária própria condizente com o temperamento do brasileiro, mas ainda estariam supostamente à margem dos circuitos intelectuais. Ambos, aquele em busca da imitação e o outro que ainda precariamente expressa a autenticidade brasileira, seriam resultado do mesmo processo de formação nacional e racial, visto que se encaixam no modelo totalizante de explicação da história nacional. Mas seriam posições divergentes e em luta pela sobrevivência, ou seja, esses modelos de comportamento representariam um momento do processo de mestiçagem, e, fatalmente, teriam como desfecho a conquista da autonomia da raça.

Sílvio Romero não somente analisa este processo, ele também o vive, justificando assim sua postura de polemista. Apesar da inevitabilidade com que entende o processo de autonomia nacional, esta se constrói mediante a luta, bem de acordo com o espírito evolucionista ao qual se filiava teoricamente. ${ }^{\text {to }}$ Sílvio Romero, apesar de todo determinismo racial que defendia, concebeu a literatura e principalmente a crítica como formas de atuação histórica, o que tornou mais complexo, e aparentemente contraditório, seu método naturalista de pesquisa. Seu pensamento era mais plástico, fundamentalmente por pretender dotar o conhecimento de um papel ativo, certo idealismo que o distanciou dos naturalistas franceses. ${ }^{\text {II }} \mathrm{O}$ intelectual/ artista, ao mesmo tempo em que seria uma determinação dos fatores raça, meio e evolução histórica, também influiria na sociedade, pois

Cada escritor é um centro de força, além de uma resultante; como centro de força, age como causa e fator de diferenciação e progresso; como resultante, é um efeito de um meio dado, de um grupo social e deve refletir as qualidades do agregado a que pertence (Romero, 1992: 79).

Essa função transformadora do conhecimento é ilustrada ainda na ideia de "espírito representativo" (Romero, I992: 70-80), inserido nesta mesma dupla função do intelectual. Então, o intelectual não se restringe à contemplação, pelo contrário, tem como principal finalidade de vida a ação, lutar por 
suas convicções por meio do próprio material de que dispõe, a escrita. Se, por um lado, os romancistas e poetas traduzem as ideias esteticamente, o crítico tem por finalidade ser uma espécie de guia dessas ideias, revelando a diretriz na qual tais poetas e romancistas devem se espelhar. E aqui retomamos o ponto acerca do ensaio como tratado por Lukács, em que o crítico interpreta personagens históricos da literatura mediante um conjunto de princípios éticos que servirão para modelar o self do público leitor, ao mesmo tempo em que serve de parâmetro ao crítico (Lukács, 1980). O próprio Romero trata a atividade crítica como um modelo para o comportamento do intelectual/artista, mostrando-lhes referenciais éticos e fornecendo o material de inspiração para os trabalhos artísticos, tal como pode ser percebido na transcrição que se segue, extraída de seu ensaio sobre Gonçalves Dias:

Não cesso de combater ideias que julgo prejudiciais ao progresso e à unidade do povo brasileiro. Em um país como o nosso, ainda novo, sem tradições bem formadas, sem coesão social bem compacta, nunca é demais insistir sobre o seu caráter popular e histórico. Ainda mais é isto indispensável, tratando-se de um poeta como Gonçalves Dias, um genuíno brasileiro, um mestiço físico e moral, que será por muitos séculos uma das mais autênticas manifestações da alma deste povo (Romero, I978: 64).

O trecho é bem ilustrativo do pensamento de Sílvio Romero, e revela a correlação que ele estabelece entre a ideia de "espírito representativo" e o processo de miscigenação no Brasil, e ainda aponta, diante disso, o papel histórico da crítica. Para Sílvio, sua finalidade como crítico é revelar a verdadeira índole artística possível a um povo como o brasileiro, o que torna o resgate de figuras como Gonçalves Dias e outros tantos "genuínos brasileiros" uma tentativa de prover os escritores contemporâneos de referenciais de imaginação artística coerentes com a raça. Este é o papel de luta e ação no qual o próprio Sílvio Romero se reconhece: combater a imitação europeia e ajudar na construção de uma identidade literária que faça parte do processo histórico brasileiro, assim como o crítico concebia tal processo.

Diante deste recorte da concepção teórica de Sílvio Romero a respeito da crítica literária é possível, agora, compreender melhor o seu posicionamento acerca de Machado de Assis registrado principalmente em seu livro sobre o consagrado autor fluminense. Para compreendermos a dura crítica que Sílvio Romero faz a Machado é necessário indicar como ele situou o primeiro presidente da Academia Brasileira frente ao processo de miscigenação no Brasil. Para Sílvio, Machado não fazia parte do rol daqueles poucos literatos capazes de expressar a "autenticidade" nacional, e, sim, da maioria, de temperamento fraco, amparada em referenciais estéticos de literaturas estrangeiras e incompatíveis com aquilo que o crítico identificava como parte da verdadeira índole mestiça. A juventude literária de Machado é descrita como uma expressão da transição literária na qual ainda sobrevivia um romantismo tardio, destoando da evolução que o país atravessava. Com a de- 
cadência "absoluta" do Romantismo, decretada pelo movimento cientificista, do qual Sílvio se gaba de ter feito parte, Machado de Assis teria realizado uma má escolha estética, optando pela imitação ao invés de fazer parte das inovações defendidas pela geração de 1870 .

Todos os elementos que Sílvio Romero mobiliza têm por pretensão corroborar sua tese dessa má escolha estética de Machado, e a análise do seu temperamento também não escapa disso. Machado é descrito como homem equilibrado, gentil e discreto, traços de personalidade, segundo Sílvio Romero, opostos ao humorismo, ao pessimismo e à ironia. ${ }^{12}$ Em certo sentido a estética adotada por Machado é considerada por Sílvio não apenas inautêntica por expressar uma contradição em relação ao seu temperamento. Tal estética é insegura devido à fragilidade do próprio temperamento de Machado, considerado por Sílvio como inadequado para qualquer tipo de atividade que exija o exercício da imaginação. À Machado restaria se resignar com a atividade mais propensa ao seu temperamento, segundo Sílvio, mais de acordo com a vida pacata de funcionário público. Assim, o ponto principal não parece ser nem o temperamento pouco artístico de Machado ou a imitação de estilos exógenos ao Brasil e ao seu caráter, mas a artificialidade e a fraqueza do seu próprio temperamento.

À luz da perspectiva de Sílvio sobre o papel da arte percebe-se que a crítica contra Machado possui duas direções, ambas relacionadas à ideia de "espírito representativo", do intelectual/artista como centro e resultante de força. Machado não desenvolveria as potencialidades de sua raça por conter e dissimular o traço expansivo do caráter coerente a um brasileiro mulato, e os efeitos dessa contenção se desdobrariam em suas características morais, estéticas e, como veremos mais à frente, também físicas. O verdadeiro brasileiro, do qual Sílvio se enxerga como representante, é bem diverso:

Nós brasileiros somos faladores, maldizentes, desrespeitadores das conveniências, assaz irrequietos, até onde nos deixa ir nossa ingênita apatia de meridionais, mas não somos pessimistas, nem nos agrada o terrível desencanto de tudo sob as formas desesperadoras dos nirwanistas a Buda ou a Schopenhauer (Romero, I992: 256).

Assim, até mesmo o caráter do primeiro presidente da Academia Brasileira de Letras é posto em suspeição, considerado artificioso, tais como suas "pretensões" ao "humorismo" e "pessimismo". De outro lado, Machado também não faria de sua literatura uma forma de ação, ou seja, não agiria com paixão. Continha todo e qualquer arrebatamento de seus sentimentos que poderiam fazer de sua pena um instrumento para a transformação do país.

Não importa isto uma aprovação a certos absenteísmos muito do gosto dos ânimos fracos, que entendem de salvaguardar a própria pureza, fugindo sistematicamente das tentações. É proceder que nunca aplaudiremos. A virtude prova-se no meio da luta. A sociedade não é um convento de monjas. Que grande mérito advém em não se cobrir do pó a quem não sai à liça do combate e deixa-se tranquilamente ficar em 
doce e sossegado aposento? Devemos todos, homens de letras ou não, interessar-nos pelas pugnas e pelas dores da pátria (Romero, 1992: 3I).

Tudo isso resultaria em um estilo sem vibração, com vocabulário pobre e mal estruturado, e sem uma descrição mais robusta e eloquente, demonstrando novamente uma simultaneidade entre "temperamento" e estilo.

O estilo de Machado de Assis, sem ter grande originalidade, sem ser notado por um forte cunho pessoal, é a fotografia exata do seu espírito, de sua índole psicológica indecisa. Correto e maneiroso, não é vivaz, nem rútulo, nem grandioso, nem eloquente. É plácido e igual, uniforme e compassado. Sente-se que o autor não dispõe profusamente, espontaneamente do vocabulário e da frase. Vê-se que ele apalpa e tropeça, que sofre de uma perturbação qualquer nos órgãos da palavra. Sente-se o esforço, a luta. "Ele gagueja no estilo, na palavra escrita, como fazem outros na palavra falada", disse-me uma vez não sei que desabusado num momento de expansão, sem reparar talvez que dava-me destarte uma verdadeira e admirável notação crítica (Romero, I992: 122).

Quase duas décadas após o texto de Machado de Assis, "A nova geração", Romero revidou o ataque que havia sofrido utilizando os mesmos argumentos: a deficiência de um estilo artificial, incapaz de expressar a ideia de maneira clara, segundo os princípios artísticos. Mas nesse trecho acrescenta que até mesmo a gagueira de Machado seria reflexo dessa contenção das características naturais de sua raça, como se resultasse do excesso de autoinspeção que marcaria seu comportamento artificial.

Como identificar, diante dessas contradições do pensamento de Romero, uma simultaneidade entre ética e forma? Certamente não podemos afirmar que os postulados naturalistas são a fonte de sua ética, como se essas ideias científicas informassem de forma coerente seu estilo de vida. Há um processo seletivo com que Sílvio Romero lida frente à ciência, apreendendo dela apenas aquilo que se encaixa em seu diagnóstico da arte e, principalmente, que justifica uma ação apaixonada no mundo. Mesmo assim, há uma forma em Sílvio, um método que gira em torno do duplo movimento embutido em seu conceito de "espírito representativo", capaz de buscar referências em positivistas e evolucionistas, a partir de uma combinação paradoxal entre distanciamento e ação. Filia-se a teorias deterministas do naturalismo e combina-as com a compreensão de uma ciência engajada, que visa o progresso. ${ }^{\mathrm{I} 3}$ Ao mesmo tempo se afasta, em parte, da concepção de um distanciamento analítico perfeito advogado por naturalistas e positivistas ao reivindicar o direito de julgar e tratar segundo critérios de valor uma obra e personagem histórico.

A teoria de "espírito representativo" proporcionaria a Sílvio abarcar o duplo movimento entre determinação e ação, pois ao mesmo tempo em que um poeta ou romancista é determinado pela evolução histórica, ele age sobre ela, ajudando a compor a tradição nacional. Ao reivindicar um papel ativo para a literatura, Sílvio acaba de justificar seu pendor para a ação também 
na crítica, dotando-a de uma função normativa que determina o que é ou não arte, baseado em seu critério de artista engajado e da arte como expressão sincera da própria raça. Tudo o que fuja da índole da raça se converte em imitação, em artificialidade, e tem como consequência a incapacidade de ação realmente justa, exatamente o ponto de demérito da obra de Machado de Assis. Ou seja, ele retira de seu modelo de compreensão da literatura uma forma de vida, uma ética que deve ser divulgada, que molda a si mesmo, ao passo que se direciona ao outro. E seu processo objetivo de pesquisa não escapa a esse mecanismo, servindo como máscara dos princípios de valor que possui e naturalizados como a própria realidade. Assim, a ciência forneceria esse traço de veracidade de seu diagnóstico, tornando o seu genuíno brasileiro em um fato concreto e, assim, dissimulando o idealismo inerente a esse seu modelo de vida.

O verdadeiro artista nacional possuiria uma índole expansiva, que não reconhece como legítimas as formalidades artificiais da vida dos salões, e Sílvio Romero, que se considera porta-voz desse temperamento expansivo do brasileiro, também não mede suas palavras pela conveniência da sociabilidade intelectual e suas formas vazias que mantém os entraves ao progresso. Assim, o seu diagnóstico a respeito da relação entre miscigenação e literatura acaba se direcionando para outro campo, com o qual aparentemente não possuiria nenhuma conexão. A arte da imitação se reproduz na vida comum, se confirmando na corrupção dos valores presente na convivência entre os intelectuais. Ou seja, assim como as obras não demonstram nenhuma autonomia de pensamento, a própria sociabilidade intelectual apresentaria como correspondência uma ética formalista e corrompida. A conversa leve e desinteressada dos salões se transforma, para Sílvio Romero, em rituais de legitimação injustificados, como se diante da imitação evidente, da inexistência de obras autênticas e de grande força, os letrados criassem mecanismos de produção de status completamente alheios ao valor intrínseco.

Com isso está preparada toda a justificativa de Sílvio Romero para o seu tom polemista, pois sua agressividade seria uma consequência necessária de seu compromisso com a verdade fundamentada "objetivamente", que lhe permite tudo dizer, e não deve ser barrado por um mundo intelectual mesquinho e dependente da imitação. A sociabilidade, então, se converte em alvo de constantes ataques, um combate não somente a pessoas, mas, principalmente, à forma de convivência entre elas, suas supostas éticas que, para o nosso crítico, prevaleciam no mundo intelectual brasileiro. Sílvio Romero encontra em Machado, portanto, um antimodelo, concentrando no escritor fluminense todas as características negativas do mestiço, que não devem servir de exemplo para a conduta intelectual, e com o qual o crítico se mede continuamente. Em contraponto com o antimodelo machadiano estaria Tobias Barreto, detentor das principais características ausentes em Machado de As- 
sis, e exaltado diante do círculo intelectual estabelecido no Rio de Janeiro com a finalidade de fornecer um modelo autêntico, uma forma de vida capaz de inspirar os outros, e com o qual se reconhece em termos éticos e, principalmente, na relação que o mestre da escola de Recife estabelecia entre o pensamento e a atuação pública. Fiquemos, entretanto, com as características do antimodelo machadiano para verificar a seguir a posição quase oposta de outro grande crítico brasileiro e desafeto de Sílvio Romero.

\section{OUTRA FACE DE MACHADO: JOSÉ VERÍSSIMO}

A formação intelectual de José Veríssimo se inicia de modo muito similar à de Sílvio Romero, pois também estreia defendendo a influência das inovações científicas para a compreensão da literatura, com a pretensão de tornar o conhecimento um mecanismo de intervenção social. Portanto, corroborava critérios evolucionistas de crítica literária ao mesmo tempo em que estava imbuído do desejo de mudança recorrente a sua geração. Seus primeiros escritos possuem um cunho sociológico, ansiando por uma descrição mais fiel da realidade e fugindo do modelo crítico de seus predecessores. O critério nacionalista também lhe era caro, e sua orientação era muito similar ao que o próprio Sílvio Romero defendia: usar o conhecimento como busca pela autonomia nacional. ${ }^{\mathrm{I}}$ Portanto, são muitas as similaridades dos trabalhos do jovem crítico com as prerrogativas de Sílvio Romero. Entretanto, ao contrário de Sílvio Romero, que na maturidade intensifica seu discurso científico e sua postura de polemista, José Veríssimo foi modificando aos poucos sua postura intelectual ao passo que se filiava a outras tendências teóricas e concentrava-se na atividade de crítica literária.

O critério nacionalista de sua juventude, que beirava à xenofobia, fez com que José Veríssimo considerasse o romance Ressurreição, de Machado de Assis, e outros romances urbanos de diferentes autores, reflexos da imitação da literatura europeia, e, por isso, obras menores do que livros com temáticas realmente "brasileiras", como O sertanejo e O gaúcho, ambos de José de Alencar. ${ }^{15}$ É interessante que tanto José Veríssimo como Sílvio Romero tenham escolhido Machado de Assis como representante da literatura de imitação logo no começo de suas carreiras, demonstrando o tipo de recepção que a geração de 1870 realizava da obra do escritor fluminense. O argumento mobilizado para a crítica depreciativa de Machado tinha o mesmo teor: era necessário que a literatura se voltasse para a "realidade" nacional, portanto, o fundamental seria retratar o mestiço, seus costumes e fisionomia. O critério nacionalista de José Veríssimo até perdoava em parte o tratamento idealizado dos romances regionais de José de Alencar pela tentativa de retratar o brasileiro, pondo tais romances, por isso, acima do livro de "costumes" de Machado, que pecaria pelo subjetivismo e ainda pelas tramas e cenários inautênticos. 
Os argumentos deste primeiro ensaio de crítica se assemelham ainda mais à percepção de Sílvio Romero quando José Veríssimo posiciona-se diante da ausência de originalidade da literatura brasileira e aponta a origem de tal problema. Para ele faltava ao Brasil uma tradição, língua e educação nacionais, e essas ausências somente seriam superadas com a atuação dos intelectuais e artistas. Essa forma de atuação, tal qual pensado por Sílvio Romero, somente seria possível com uma literatura comprometida, imbuída do espírito científico, tendo especial destaque a própria crítica, que seria instrumento de orientação para a reconstrução nacional ao indicar os caminhos para uma linguagem mais objetiva capaz de retratar a "realidade" (Barbosa, 1974: 96-97).

A partir de I89ı, com sua ida definitiva para o Rio de Janeiro, verificam-se algumas mudanças na percepção de José Veríssimo. Como revela o próprio crítico em artigo de jornal um mês após a morte de Machado, ${ }^{16}$ ao chegar ao Rio de Janeiro, ele foi imediatamente procurar Machado de Assis, motivado por admiração de longa data. E antes mesmo desse encontro eles já haviam trocado correspondência em abril de I883, cuja iniciativa foi do próprio José Veríssimo, que convidava o ilustre fluminense para ser colaborador de sua recém-fundada Revista Amazônica, e lamentava o pequeno público de que dispunha (Assis, 2009: 254). Essa postura de José Veríssimo revela possivelmente algumas alterações do seu julgamento a respeito de Machado de Assis antes mesmo de sua mudança para o Rio de Janeiro, pois, é válido lembrar que no ano em que os dois trocam cartas, Machado já era o autor consagrado de Memórias póstumas, livro que teve uma boa receptividade na crítica (Magalhães Júnior, I98I: I-I9) e considerado um dos símbolos do pessimismo em literatura no Brasil. É como se antes mesmo de sua ida para o Rio de Janeiro o futuro crítico se visse diante de um impasse, entre a crítica naturalista, à qual se manteria relativamente fiel até I89I, e, de outro lado, uma tendência ao pessimismo, ${ }^{17}$ semelhante ao de Machado, com quem já manifestava intenção de aproximação. Segundo Barbosa, citando Otto Maria Carpeaux, a aproximação entre eles se dava devido a certa afinidade baseada em "um realismo pessimista de quem tinha a consciência das fraquezas humanas" (Carpeaux apud Barbosa, I974: 56). Afora o problema de considerar Machado de Assis um autor situado na escola realista, há, de fato, uma aproximação de visão de mundo entre os dois. José Veríssimo, já em sua juventude manifestava certo pendor para um diagnóstico do Brasil não tão promissor, em contradição com sua postura teórica combativa.

A mudança a respeito de Machado de Assis aparece em um artigo de jornal, ${ }^{18}$ em I892, ao resenhar o livro Quincas Borba. Neste artigo já não há nenhum resquício do seu texto da juventude, tratando Machado de Assis com deferência e reavaliando completamente seu parecer do primeiro texto, até mesmo mencionando o livro Ressurreição, quando Machado já se mostrava um 
"romancista observador". O mais significativo desse artigo, no entanto, é a mudança de seu critério de análise da obra de Machado de Assis, pois nota-se uma transformação íntima a respeito da própria percepção da literatura e da crítica. Esse é o famoso ensaio em que José Veríssimo afirma não ser possível abordar a obra de Machado mediante o critério nacionalístico, reportando-se diretamente a Sílvio Romero como um dos que injustamente desmereciam o escritor fluminense por não enxergar nele a temática realmente brasileira e por não contribuir para

[...] a determinação do caráter nacional, ou, em outros termos, qual a medida do seu concurso na formação de uma literatura, que por uma porção de caracteres diferenciais se pudesse chamar conscientemente brasileira (Magalhães Júnior, I98I: 193).

Essa exceção com que José Veríssimo caracteriza a obra de Machado de Assis não significa apenas uma concessão de valor ao autor de Quincas Borba diante do método naturalista de crítica, e, sim, a própria contestação desse método para a abordagem da sua obra, e, talvez, também como fundamento efetivo de crítica. Parece que José Veríssimo começa a rejeitar, em parte, todo método que defina de forma muito estrita o que é a arte, chegando a afirmar que cada vez menos acredita na eficácia das escolas e menos ainda no "emprego sistemático de fórmulas críticas". ${ }^{19}$ Ou seja, sua releitura de Machado de Assis é parte de um processo de relativização da interpretação determinista da obra artística, questionando até que ponto as teorias raciais e do meio físico são suficientes para apreender, de fato, uma forma superior de $\operatorname{arte},{ }^{20}$ que se destacasse e ganhasse distinção no meio local.

Para chegar a isso, José Veríssimo ataca em duas direções: a primeira visa diminuir a importância da escola literária, destacando a necessidade de maior liberdade de imaginação estética aos escritores; a segunda se volta para a própria crítica, ao apontar para os limites das teorias literárias e o prejuízo decorrente do emprego de fórmulas críticas para a apreensão da obra de arte imortal. Esses dois pontos da crítica de José Veríssimo conduzem ao mesmo lugar, à tentativa de justificar o caráter individualizado do grande artista, tratando-o como um indivíduo complexo que de certa forma se descola do meio no qual está imerso e produz algo novo e digno de fazer parte da "eterna beleza da obra literária" (Veríssimo, I977: 204). O primeiro front tem por objetivo avaliar a relação entre as escolas literárias e o escritor, e apesar do caráter de generalidade da questão que desejava, era evidente que seu foco era o movimento literário naturalista. Para José Veríssimo, as escolas concorrem pela supremacia estética, lutando entre elas pela definição de quais postulados teóricos representam efetivamente o valor artístico. Então as escolas motivadas pela disputa acabam por lidar de modo apaixonado com a arte, enxergando padrões e limites normativos do fazer literário, e, assim, sufocando a verdadeira expressão artística baseada em certa liberdade sub- 
jetiva. A vitória de determinada escola sobre as demais a encheria de presunção, como se toda a história literária concorresse para a sua formação, a forma última e definitiva de arte. Assim relata José Veríssimo:

A tarefa da crítica é compreender. Por mais falsa e censurável que lhe pareça, pois, este critério das escolas literárias triunfantes ou em via de triunfo, é sua obrigação entendê-lo, quase como uma fraqueza humana, necessária e indispensável à vitória das ideias. Não se triunfa sem fé, e a fé não vai sem um pouco de fanatismo (Veríssimo, I977: 204).

A escola literária triunfante, portanto, se define pelo caráter normativo, fanático, com que lida com a estética, e seriam os naturalistas os recém-ganhadores de um embate, os novos portadores dos significados da literatura, que agiriam no sentido de neutralizar qualquer outro movimento ou nova estética que viesse a surgir. Assim, as características individuais do artista se veem oprimidas pela visão totalizante e estreita do fazer artístico, sendo podadas e condicionadas a cumprir com os preceitos normativos de determinada escola.

O segundo ponto da revisão teórica de José Veríssimo se volta para a indicação de como determinadas críticas literárias cumprem justamente esse papel coercitivo dos movimentos literários, pois na sua busca de compreensão da obra acabam por deixar preponderar os critérios normativos da escola que representam. Assim, em vez de utilizar as teorias como recurso de análise, tais críticas, ou mais diretamente tais críticos, convertiam seus pressupostos em parâmetro de definição do que é ou não arte. Portanto, é como se o movimento tivesse pretensões de perpetuar-se como forma de apreensão da literatura, traduzindo tudo à luz de sua própria percepção estética. José Veríssimo exemplifica esse ponto a partir do próprio Machado, ao afirmar não ser possível abordar a sua obra pela via "nacionalística". Com isso, José Veríssimo refuta a direção fundamental da teoria crítica naturalista: a relação da arte com o meio, raça e os fatores históricos. Como pensar a obra de arte imortal mediante esses juízos objetivos da ciência crítica naturalista? As determinações do meio, da raça e do momento histórico seriam capazes de explicar a individualização de uma obra e sua inserção no rol da grande literatura? Esse é o ponto fundamental de confirmação da conversão de José Veríssimo, pois explica como o crítico deixa de tratar a obra de Machado como pura imitação da estética estrangeira para considerá-lo um grande escritor.

José Veríssimo não abandona de todo a crítica naturalista, e até mesmo os pressupostos positivistas e evolucionistas, mas minimiza seus principais postulados teóricos, demonstrando a necessidade de combiná-los a outros critérios para a apreensão de determinado autor. Machado seria um exemplo disso justamente por escapar a essas determinações, estando à parte "do conjunto de fatos de toda ordem que eu chamaria a Vida Brasileira". ${ }^{21}$ No primeiro artigo sobre Machado, José Veríssimo atacava o escritor flumi- 
nense devido à sua imitação, pois não seguia a índole do povo, produzindo uma arte indiferente às possibilidades estéticas de sua raça. Já neste segundo ensaio, inverte completamente sua abordagem, valorizando positivamente o descolamento de Machado do meio, e também sua raça, como se este fosse o ponto que caracterizasse a genialidade de sua obra. É necessário lembrar que José Veríssimo ainda está imbuído, como já foi dito, dos pressupostos cientificistas, e, portanto, mesmo que discorde de certos diagnósticos ainda acredita na existência de uma realidade concreta a ser apreendida pelo conhecimento. Ou seja, a relativização da relação entre o grande escritor e o meio não significou que ele tenha questionado a importância da experiência histórica brasileira e de outras nações como principal ponto de partida para as investigações sobre a literatura; o que ocorreu de fato foi uma valorização da genialidade do grande escritor, que, devido a fatores especiais, principalmente em decorrência do próprio temperamento, consegue se apartar das determinações e produzir a grande obra. Assim, José Veríssimo tece o elogio a Machado justamente em relação a esse ponto, ao distanciamento, à possibilidade de se sobrepor à realidade mesquinha e desencantada que se desenhava diante de suas lentes pessimistas.

João Alexandre Barbosa em seu estudo sobre José Veríssimo atribui o "grão de ironia e de ceticismo" do crítico paraense à desilusão gerada com a esperada República, e relaciona o momento político social de início da nova forma de governo com a tendência do crítico ao afastamento. Uma frustração com o próprio modelo de intelectual da geração de I870, que acreditava poder transformar a sociedade por meio da propagação das novas ideias científicas, e que defendeu e lutou pela implantação da República. Diante deste quadro só restaria ao intelectual reconhecer sua impotência frente à história e tentar preservar seus princípios e a si mesmo no seu próprio recolhimento (Barbosa, I974: II2-I56). Assim, a postura de intelectual combativo, que assume uma retórica de ataque como meio de ação intelectual e desrespeita propositalmente a conversação comedida, parece passar a ser identificada por José Veríssimo como um fruto indesejável da geração de I870, como reflexo de desejos de transformação imponderados e afoitos.

José Veríssimo, durante o processo de redefinição de sua ética/estética crítico-literária passa a aspirar a outro modelo de intelectual: um membro da sociedade austero, reservado, e que prefere a contemplação irônica da "vida", ainda que acompanhada por uma forma de melancolia impotente. Porém, esse estado melancólico e irônico forma a base de certo senso de distinção, como se a crítica resignada e desapaixonada das fraquezas humanas representasse o próprio esforço por elevar-se moralmente diante de seu entorno. Uma busca por afirmar positivamente a melancolia e a insegurança para agir no mundo, através desse juízo elevado de si mesmo. A partir disso, a ação política apenas atrapalharia o desenvolvimento do verdadeiro gênio literário, pois 
[...] a seu ver era suficiente assentar que o escritor brasileiro, dominado pelas agitações políticas e sociais, nada poderia produzir de duradouro. Para que isto se pudesse realizar era necessário ou o tempo, capaz de oferecer uma ótica adequada de distanciamento, ou o talento solitário de um Machado de Assis, segundo Veríssimo, marchando indiferente à corrente de sua época, guiado apenas por um projeto de obra pessoal (Barbosa, I974: I28).

O ensaio crítico de José Veríssimo, portanto, buscava o reconhecimento daquilo que gostaria de se tornar no plano teórico e também subjetivo. Talvez a sua narrativa da história literária brasileira aponte, em seu horizonte, o modelo intelectual deixado por Machado de Assis, com a intenção de fornecer o seu próprio caminho de autotransformação e modelagem.

A depreciação da luta como forma de vida conduz, ainda, a uma maneira muito específica de se relacionar com o mundo, e similar ao personagem de Machado de Assis, Jacobina, de seu conto "O espelho: esboço de uma nova teoria da alma humana", José Veríssimo passa a identificar a discussão e a polêmica como uma descompostura. A discussão seria tratada como uma forma desesperada de confirmar determinados princípios à força, na tentativa de legitimá-los perante o outro e aos olhos do público, em que se comprova o próprio valor apenas com o "roubo" da honra do oponente, como em um duelo. Esta forma de convívio intelectual é interpretada pelo maduro José Veríssimo como algo inócuo para o desenvolvimento intelectual, como se se tratasse de sobrevivências do estado de selvageria. Portanto, uma postura completamente contrária à defesa de Sílvio Romero dessa forma de interação como meio de expressão da força do indivíduo e da consequente evolução humana.

Para José Veríssimo, a relação entre os intelectuais, e destes com o mundo, deve se dar em perfeita harmonia, sem os constrangimentos das expansões de personalidade, devendo-se apenas debater ideias de forma polida, evitando qualquer tom apaixonado. Dessa forma, José Veríssimo acaba por justificar certos modos da linguagem cortesã, valorizando o tom reservado das conversas leves e contrário ao comportamento expansivo que não reconhece os limites do tato. A mesma "sociabilidade" vista com tamanha negatividade por Sílvio Romero é transformada em ideal de convivência social por José Veríssimo. É fácil visualizar essa tensão a partir do tratamento que o já maduro José Veríssimo dispensa ao seu principal desafeto, ao julgar, em seu ensaio Post Scriptum, escrito em 30 de dezembro de 1906, o discurso proferido por Sílvio Romero na solenidade de recepção de Euclides da Cunha para a Academia Brasileira, em I8 de dezembro de I906. Para José Veríssimo, o discurso acadêmico

Pode exprimir, e feito por tais homens tem exprimido, os mais alevantados, os mais livres, os mais novos pensamentos. Tem, porém, a sua maneira, se quiserem a sua retórica própria, que é aliás apenas a de um salão de boa companhia. Neste todas as opiniões e ideias podem ser aventadas e sustentadas, contanto que não ofendam susceptibilidades respeitáveis ou veneráveis delicadezas de sentimento, e a linguagem e 
os gestos se acomodem ao ambiente social. A própria existência de qualquer sociedade policiada supõe o sacrifício das expansões demasiado pessoais, em proveito das vantagens que tira o homem da sociabilidade. Sob este aspecto só é verdadeiramente livre o selvagem ou o grosseirão. A prolixidade somente já é num salão ou numa Academia um documento de mau gosto e de má-criação (Veríssimo, 2001: 274).

É interessante verificar, no entanto, que o próprio José Veríssimo recorre à polêmica para afirmar o caráter desagradável e hostil de tal forma de expressão/relação, ${ }^{22}$ reforçando ainda mais a tese da sua busca pela conversão. Seu processo de automodelagem, a intenção de fixar um novo parâmetro de conduta a partir da crítica a Machado de Assis, tomando-o como exemplo ético e artístico a ser seguido, de início contou com formas retóricas de autoafirmação similares ao modelo que considerava indesejável. Este contras te reforça, assim, as nuances de sua intenção, da tentativa de se inspirar em um modelo que, em seu caso, era praticamente oposto à sua primeira formação intelectual.

\section{ALGUMAS CONSIDERAÇÕES FINAIS}

A identificação das diferenças entre José Veríssimo e Sílvio Romero não visam apontar simplesmente o caso particular da relação entre eles, e, sim, demonstrar duas orientações de ética intelectual sendo expressas naquele momento e que podem ser apreendidas a partir de seus textos sobre Machado de Assis. Ou seja, trata-se de perceber que este momento histórico é palco, também, de uma disputa pelo modelo de intelectual que se queria para o país, simultânea à formação das bases para as grandes interpretações nacionais. Talvez, estes dois modelos possam ser melhor identificados a partir da noção de vocação.

Sílvio Romero concebe a crítica como um espaço privilegiado de embate, como o principal palco da arena pública. Assim, toda a teoria mobilizada pretende diferenciar e confrontar os discursos e visões de mundo mediante o enfrentamento entre os intelectuais. Por isso a escrita deve ser pulsante, toda submetida à retórica do púlpito e da confrontação constante de valores. Desta forma, criticá-lo pela ausência de serenidade seria apenas confirmar aquele que foi seu maior propósito, a disposição para a luta e uma atração pela aventura e risco. Para Sílvio Romero, a "vocação" do intelectual significa obedecer ao chamado da esfera pública, do tumulto entre os confrontos de valores e da possibilidade de extrair dessa luta a "ideia" melhor adaptada à evolução do cenário nacional.

José Veríssimo, ao longo de toda sua vida também se preocupou com o que considerava ser o maior problema da sociedade brasileira, a educação; portanto, não se desviou de um compromisso e responsabilidade com as questões nacionais. Não fez sempre da escrita uma espada como Sílvio Romero, mas, ainda assim, também operava com uma noção de vocação intelectual 
como um sacrifício à vida pública. Os seus ensaios sobre Machado evidenciam, no entanto, outro pendor e atração: o ceticismo e a aspiração ao equilíbrio. A atuação do intelectual e as expectativas em balizar seu valor a partir do sucesso de suas ações, na possibilidade de contribuir para a melhoria da sociedade, é um risco que José Veríssimo parecia analisar sob um prisma mais melancólico. O mundo público e a própria vocação intelectual, entendida no sentido de responsabilidade e compromisso com a realidade - marcada pela ideia de progresso, corrente no período -, são apresentadas por José Veríssimo como aspirações quase inalcançáveis e com grande potencial de frustração. A literatura e a sociabilidade intelectual seriam refúgios dessas turbulências, uma espécie de sociedade ideal, na qual os altos valores buscados poderiam se tornar o padrão elementar de conduta. Assim, os escritos de José Veríssimo sobre Machado apontam para uma espécie de agorafobia, certa recusa pelo embate público. Isto, em certa medida, contribuiu para a formulação de outra acepção possível à noção de vocação literária, mais distanciada, e que conferia valor e importância justamente ao isolamento subjetivo, ao cultivo interior de um equilibrado e cético Machado de Assis.

São posturas intelectuais distintas que revelam padrões específicos de convivência social. As interpretações relativas a Machado de Assis, para além da estratégia de convivência interessada, estão vinculadas a tais visões de mundo, aos princípios éticos e estéticos que estão na base dos ideais de sociedade e de artista/intelectual apresentados no período, e que, em grande medida, são exemplarmente defendidos por José Veríssimo e Sílvio Romero. 
Maurício Maia Aguiar é doutor em Sociologia pelo Instituto de Estudos Sociais e Políticos da Universidade do Estado do Rio de Janeiro (IESP-UERJ) e professor de sociologia da Universidade Federal de Campina Grande (UFCG). Suas áreas de interesse são pensamento social brasileiro e sociologia da cultura, com foco nas sociabilidades artísticas e intelectuais brasileiras do final do século XIX. Publicou recentemente o artigo "Objetividade e aventura: Machado de Assis a partir do casmurro Sílvio Romero" (20I4). 


\section{NOTAS}

I José Veríssimo e Silvio Romero parecem condensar, em seus julgamentos, com maior sofisticação teórica, o posicionamento mais amplo das críticas literárias publicadas na época (Aguiar, 2012). A grande maioria apoiava Machado de Assis, como Capistrano de Abreu, Lúcio de Mendonça, Valentim Magalhães, entre outros, enquanto uma minoria atacou, em algum momento, a literatura machadiana, como Araripe Junior e Múcio Teixeira, que o designou como um "estéril versejador de meia tigela", não compreendendo a sua suposta "[...] imperturbabilidade, permanente e fria, diante dos grandes acontecimentos políticos, sociais e humanos do nosso agitado tempo, em que foi abolida a escravidão da sua raça, dele, mulato com fumaças de branco, que torce o nariz chato e grosso a todos os seus parceiros menos afortunados" (Múcio Teixeira, Jornal do Brasil, 20 e 27 de maio de I9oI apud Machado, 2003: 24I).

2 Essa nova onda cientifizante que marca o referido decênio e que terá braços na poesia, no romance, nos estudos do direito e até nas ideias políticas são mencionadas pelo próprio Sílvio Romero na sua introdução a um livro de Tobias Barreto, coletânea de diversos ensaios, organizado pelo próprio Sílvio e intitulada Explicações indispensáveis (ver Barreto, 1926, p. XXVI apud Barbosa, I974: 28).

3 Silvio Romero, em seu já mencionado livro sobre Machado de Assis, descreve Taine como o reformador da crítica do século XIX (Romero, I992: I64). E Antonio Candido, em sua tese de doutoramento que aborda a teoria crítica de Sílvio Romero, afirma que este bem cedo conheceu Taine, "em cuja leitura se formou" (Candido, I988: 50).

4 Os poemas foram escritos entre os anos de 1869 e I873, e somente reunidos em livro em 1878 , quando havia se mudado para Paraty, onde cumpria magistratura. Ele se mudaria para o Rio de Janeiro no ano seguinte, em I879, portanto, provavelmente, esse seu livro teve certa divulgação na capital do Império (Candido, I988: 36-37).

5 Ensaio publicado na Revista Brasileira, em $\mathrm{I}^{\circ}$ de dezembro de 1879 (Assis, s/d).

6 O conceito de sociabilidade aqui assumido é correlato ao desenvolvido por Simmel, cujo significado está relacio- 
nado com a ideia de uma conversação de salão, em que os participantes evitam qualquer atitude inconveniente à harmonia desejada. Para isto é necessário uma forma de convivência aparentemente superficial, em que os temas são abordados de maneira leve e adversa a qualquer tipo de expansão de personalidade; portanto, uma espécie de universo à parte da sociedade vivenciada de maneira igualitária entre os participantes (Simmel, 2006). O termo literária, desse modo, somente acrescenta a peculiaridade que tal tipo de relação engendra, envolvendo intelectuais e assuntos mais precisos, porém, mantendo a característica de sociabilidade.

7 As categorias mencionadas são uma adaptação da teoria da literatura de Taine, originalmente, estipuladas por raça, meio e momento (Romero, I978: 39).

8 Sílvio Romero em seu texto "Gregório de Matos" (Romero, I978: 55), menciona seu conceito de mestiçagem moral e o exemplifica a partir da relação entre o escravo e o senhor de engenho no Brasil, em influências mútuas derivadas da convivência. Bastante similar à tese defendida por Gilberto Freyre em Casa-grande e senzala.

9 Sílvio insinua que Machado é um dos autores brasileiros que é de bom tom elogiar "para inglês ver", ou seja, para manter simplesmente as aparências de grande valor sem discutir profundamente seus textos. Sílvio pretendia, as sim, descrever o mecanismo convencional entre os letrados brasileiros de seu período (Romero, I992: 56).

Io Roberto Ventura afirma que a polêmica, na qual é comum o uso de uma linguagem de luta e "predicados como valentia e coragem", formou-se a partir de uma espécie de sincretismo entre um código de honra tradicional e a compreensão evolucionista da luta pelas ideias como forma de aperfeiçoamento cultural e social. Pretendia, assim, apresentar uma correlação entre o método crítico e forma de convivência entre os intelectuais do período (Ventura, I99I: 80).

I I No seu primeiro artigo acessível, "Realismo e idealismo", publicado originalmente no jornal O Movimento, em 23 de maio de 1872 , e incorporado posteriormente ao livro Es tudos de literatura contemporânea, publicado em I885, Sílvio 
Romero defende a correspondência entre o realismo e o idealismo, demonstrando que ambos são complementares, e não contraditórios (Candido, I988: 36-38).

I2 Grande parte das resenhas literárias publicadas nos jornais da época tratava os romances de Machado a partir dessas categorias estéticas, e o livro de Sílvio Romero sobre Machado aborda longamente cada um desses supostos desencontros entre a personalidade de Machado e o humorismo, pessimismo e a ironia.

I3 Muitas das opções intelectuais de Sílvio foram negociadas com as contingências do momento, portanto, a crítica de cunho positivista, naturalista e até posturas idealistas eram utilizadas seletivamente na medida em que eram úteis para a compreensão e atuação no processo histórico brasileiro (Candido, I988: I24).

I4 A estreia de José Veríssimo ocorre em I878, com o livro Primeiras páginas, composto de vários trabalhos do autor, como Quadros paraenses, Viagens no sertão, e dois estudos, entre eles: As raças cruzadas do Pará e a literatura brasileira: sua formação e destino. A partir desses primeiros textos uma sequência de seis pequenas narrativas ficcionais, de forte cunho realista; uma espécie de etnografia da cultura amazônica descrita em viagens do crítico; um estudo etnográfico ainda sobre a Amazônia e ainda um ensaio de crítica literária - João Alexandre Barbosa traça o perfil do jovem intelectual como membro da geração contestante de 1870 , comungando as ideias e valores dos principais representantes deste movimento (Barbosa, I974: 27-39).

I5 Este ensaio crítico intitulado A literatura brasileira: sua formação e destino, publicado originalmente no livro Primeiras páginas, foi relançado em trabalho posterior de José Veríssimo, Estudos brasileiros. Nesta nova versão, o próprio José Veríssimo, no Prefácio, afirma não concordar com alguns de seus posicionamentos, em um extenso pedido de desculpas (Barbosa, I974: 30-3I).

I6 Artigo publicado no Jornal do Commercio, em 29 de outubro de I908 (Magalhães Júnior, I98I: I78-I79).

I7 José Veríssimo, desde seu primeiro ensaio crítico, A literatura brasileira: sua formação e destino, já manifestava um pendor para o pessimismo ao desculpar, em parte, a timidez da literatura brasileira devido à ausência de um públi- 
co de leitores. Como se a baixa qualidade da literatura produzida se devesse a uma tentativa dos literatos em tornarem-se acessíveis ao leitor de pequena erudição. Esse tipo de postura põe um impasse para a transformação do país, que viveria "o espetáculo de um país novo com os vícios das sociedades decadentes" (Barbosa, I974: 34).

I8 "Às segundas-feiras: um novo livro do Sr. Machado de Assis" (Jornal do Brasil, I I de janeiro de I892). Posteriormente, este artigo seria reeditado em seu livro Estudos brasileiros, $2^{a}$ série, publicado em I894 com o título de "Machado de Assis - Quincas Borba” (ver Magalhães Júnior, I98I: I92)

I9 Sílvio reproduz um grande trecho deste ensaio em seu livro sobre Machado de Assis de I897, para depois rebater a crítica de José Veríssimo afirmando que, querendo ou não, Machado deve ser visualizado pelo método nacionalístico, pois qualquer escritor brasileiro reproduz, de alguma forma, a índole nacional, e o autor de Falenas não sairia à lei comum, "e ai dele, se saísse. Não teria valor" (Romero, 1992: 65-66).

20 O crítico chega a essas concepções críticas em outro ensaio intitulado $O$ naturalismo na literatura brasileira, texto publicado em I894 no mesmo Estudos Brasileiros, $2^{a}$ série. Portanto, é praticamente simultâneo ao texto sobre Machado de Assis mencionado anteriormente e confirma os mesmos pontos de renovação do seu pensamento (Veríssimo, 1977: 204).

2 I "Às segundas-feiras: um novo livro do Sr. Machado de Assis" (Jornal do Brasil, I I de janeiro de I892, apud Magalhães Júnior, I98I: 194).

22 Após o texto de 1894 é iniciada uma sequência de artigos de José Veríssimo e Sílvio Romero nos quais se atacam e deslegitimam um ao outro como críticos literários. Apesar das ofensas pessoais que o próprio José Veríssimo utiliza na contenda, o crítico paraense sempre se arroga do argumento da deselegância de tal forma de discussão de “ideias". Contudo, parece que José Veríssimo adota definitivamente o "tédio a controvérsia", de inspiração machadiana, ao deixar sem resposta o artigo de Sílvio Romero "Zeverissimações ineptas da crítica", de Igog (Ventura, I99I: II7). 


\section{REFERÊNCIAS BIBLIOGRÁFICAS}

Aguiar, Maurício Maia. (2012). Retratos de Machado de Assis: sabedoria, genialidade e melancolia na crítica literária fin de siècle. Tese de Doutorado. IESP/Universidade do Estado do Rio de Janeiro.

Aguiar, Maurício Maia. (2014). Objetividade e aventura: Machado de Assis a partir do casmurro Sílvio Romero. Machado de Assis em linha, 7/13, p. 44-62.

Assis, Machado de. (2009). Correspondência de Machado de Assis: tomo II, I870-I889. Rio de janeiro: ABL.

Assis, Machado de. (s/d). Crônicas, crítica, poesia, teatro. São Paulo: Cultrix.

Barbosa, João Alexandre. (1974). A tradição do impasse: linguagem da crítica e crítica da linguagem em José Veríssimo. São Paulo: Ática.

Barreto, Tobias. (I926). Vários escritos. Rio de Janeiro: Edição do Estado de Sergipe, p. XXVI.

Candido, Antonio. (I988). O método crítico de Sílvio Romero. São Paulo: Edusp.

Carpeaux, Otto Maria. (I949). José Veríssimo - crítico da nacionalidade. Correio Paulistano, I4 de dezembro.

Lukács, Georg. (1980). Soul and form. Cambridge, MA: The MIT Press.

Machado, Ubiratan. (2003). Machado de Assis: roteiro de consagração. Rio de Janeiro: Eduerj.

Magalhães Júnior, Raimundo. (I98I) Vida e obra de Machado de Assis. Maturidade. Rio de Janeiro: Civilização Brasileira (vol. 3).

Rocha, João Cezar de Castro. (2004). O Ruído das festas e a fecundidade dos erros: como e porque reler Sílvio Romero. In: $O$ exílio do homem cordial: ensaios e revisões. Rio de Janeiro: Ed. Museu da República.

Romero, Sílvio. (I992). Machado de Assis: estudo comparativo de literatura brasileira. Campinas: Ed. Unicamp.

Romero, Sílvio. (1978) Teoria, crítica e história literária. São Paulo: Edusp.

Romero, Sílvio. (I878). Cantos do fim do século. Rio de Janeiro: Typografia Fluminense. 
Simmel, Georg. (2006). A Sociabilidade: Exemplo de sociologia pura ou formal. In: Questões fundamentais da sociologia. Rio de Janeiro: Zahar.

Ventura, Roberto. (I99I). Estilo Tropical: história cultural e polêmicas literárias no Brasil I870-I9I4. São Paulo: Companhia das Letras.

Veríssimo, José. (200I). Que é literatura? E outros escritos. São Paulo: Landy Editora.

Veríssimo, José. (1977). José Veríssimo: teoria, crítica e história literária. São Paulo: Edusp.

Weber, Max. (I992). A objetividade do conhecimento na ciência social e na ciência política. In: Metodologia das ciências sociais. Campinas: Cortez. 


\section{MACHADO DE ASSIS EM PERSPECTIVA: \\ OS OLHARES DIVERGENTES DE SILVIO ROMERO E JOSÉ VERÍSSIMO}

Resumo

José Veríssimo e Sílvio Romero foram rivais nas mais diversas instâncias: concepção de crítica literária, posição do intelectual e do artista na sociedade brasileira e o papel da polêmica como atuação pública. Essas e outras divergências se evidenciam no retrato esboçado por cada um sobre o primeiro presidente da Academia Brasileira de Letras. Esses perfis de Machado de Assis, dessa maneira, encarnam projeções intelectuais opostas, e a disputa entre elas visa a estabelecer o modelo de artista nacional e, principalmente, seu papel em face do momento histórico que se desenha de diferentes formas por ambos. A exposição desta divergência nos permite visualizar o ambiente intelectual do período e as interfaces entre as interpretações da "realidade" brasileira com os referenciais éticos e estéticos formulados no período.

\section{MACHADO DE ASSIS IN PERSPECTIVE: THE DIVERGENT VIEWS OF SILVIO ROMERO AND JOSÉ VERÍSSIMO}

José Veríssimo and Sílvio Romero were rivals in many different aspects regarding the conception of literary criticism, the position of the intellectual and the artist in Brazilian society and the role of controversy as public acting. These and other disagreements are evident in their portrait of Machado de Assis, the first president of the Brazilian Academy of Letters. These different profiles embody opposite intellectual ideals that dispute the establishment of a national model of the artist and, mainly, its role in the historical moment. It is argued that this disagreement showcases the interfaces between their interpretations of Brazilian reality and the ethical and aesthetic references of their intellectual environment.
Palavras-Chave

Machado de Assis; Sílvio Romero; José Veríssimo; Crítica literária; Sociabilidade.

Keywords

Machado de Assis; Sílvio Romero; José Veríssimo; Literary criticism; Sociability. 